\title{
GROWTH OF LUCERNE FOLLOWING DEFOLIATION
}

\author{
R. H. M. LANGer AND J. M. KEOGHAN \\ Lincoln College, Canterbury
}

\begin{abstract}
Summary
In a simulated sward of Wairau lucerne cut at an immature stage of growth to leave a stubble of $10-11 \mathrm{~cm}$, removal of all or one-half the residual leaf area resulted in an initial decline of root weight and low or negative crop growth rates. After 4 weeks, top dry weights showed no significant differences. Calculation of net assimilation rates suggested that previously shaded foliage may initially have had low photosynthetic efficiency following exposure to full light after cutting. Since, in addition, the major part of the regrowth came from the crown shoots, it is concluded that few advantages accrue from leaving a tall stubble.
\end{abstract}

\section{INTRODUCTION}

THE BASIC PRINCIPLES involved in the recovery of lucerne following defoliation have been the subject of intensive research for many years. With the passage of time there have been various changes of emphasis, different aspects have been singled out for particular study, and only gradually a balanced view has emerged which has placed into proper perspective a number of factors which at one time were considered to be all-important individually.

In a widely quoted publication, Graber et al. (1927) stated that in lucerne new top growth, especially in the early stages, is initiated and developed at the expense of previously accumulated organic reserves, and that the quantity and quality of these reserves limit the amount of both top and root growth that will occur. The evidence supporting the view that the available carbohydrates of the roots at the time of cutting act as reserves determining the ability of the plant to resume growth was summarized by Weinmann (1948), but others have challenged this interpretation by drawing attention to the role of carbohydrates in respiration following the removal of leaves (May, 1960), the use of other metabolites as respiratory substrate following severe defoliation (Davidson and Milthorpe, 1966), or the loss of absorbing surfaces by the roots (Mitchell and Denne, 1967).

Following the work of Watson (1947) with crop plants, leaf area index (LAI) has been widely accepted as a 
determinant of crop growth rate. This approach was extended by Davidson and Donald (1958) and Brougham (1956) to include the growth of pasture legumes and grasses following defoliation. In lucerne, Langer and Steinke (1965) drew attention to the potential importance of the residual leaf area which remains on the stubble following a cut when repeated close cutting had reduced root weights and depressed the recovery of plants growing in pots. A more recent study (Silva, 1968) has confirmed that recovery of lucerne when root carbohydrate levels are low depends on the amount of foliage remaining after cutting. Hodgkinson (1970) has shown that organic root compounds labelled with ${ }^{14} \mathrm{C}$ prior to herbage removal are used as respiratory substrate and to a lesser extent translocated into new shoots for the first 20 days of regrowth. In the field there may be less advantage in retaining foliage on the stubble by raising the height of cutting than in pot experiments. This applies particularly to swards which for maximum yield are cut infrequently, because under these conditions increasing leaf age and deteriorating light penetration lead to a rapid loss of foliage in the basal zones. For example, Keoghan (1966) showed that LAI in the bottom $10 \mathrm{~cm}$ of a sward decreased from 0.76 to 0.14 between 15 and 34 days after defoliation. There is also the question of whether basal leaves can adapt rapidly to a changed environment and photosynthesize efficiently once they are exposed to high light intensity following removal of the upper layers of the sward.

Quite apart from the energy required for regrowth, whether from current photosynthesis or supplied by the roots, there is one further factor which has received attention by several workers. This concerns the presence and stage of development of buds and shoots capable of resuming growth following defoliation. For example, Smith (1962) has demonstrated that in Wisconsin the cutting frequency imposed on Vernal lucerne should be determined by the periodicity of new buds which appear when the plant has reached a mature stage of growth. In a very detailed study of spaced plants, Leach (1968) examined the relative importance of different sites from which new growth appears, such as buds situated on the crown or in axillary positions on the stubble.

It seems, therefore that a thorough analysis of how lucerne recovers from cutting should include all three factors-root materials, residual leaf area, and available growing sites. Such a study should be conducted under sward conditions, because there is ample evidence to show 
that the abundance and longevity of basal leaves tend to be greater in spaced plants, especially in controlled environments (Keoghan, 1970). The following experiment represents an approach in this direction.

\section{MATERIALS AND METHODS}

Cuttings from a field stand of New Zealand Certified Wairau lucerne were taken in May and June, rooted, inoculated and transplanted into $6 \mathrm{~cm}$ peat pots. In November these plants were planted out $6.5 \mathrm{~cm}$ apart, to give a density of $237 / \mathrm{m}^{2}$, into large boxes measuring $142 \mathrm{X}$ $119 \mathrm{~cm}$ and $40 \mathrm{~cm}$ deep, filled with a mixture of two parts soil to one of sand. Six replicate model swards in separate boxes were established in this way, kept out of doors, and watered regularly. On being placed into position, each plant was cut to about $3 \mathrm{~cm}$ of the soil surface. The first regrowth period of 50 to 53 days, at the end of which plants were flowering, allowed establishment of the swards. Following a cut at this stage, two further harvests were taken at the pre-bud stage, with the intention of reducing plant vigour. The last of these cuts left a stubble of $10-11 \mathrm{~cm}$, and this was prepared to give three conditions. In Treatment 1 all residual leaves were removed, in Treatment 2 approximately only one-half of these leaves were removed so that their age distribution was similar to that in Treatment 3 in which all residual leaves were left intact. Each block (box) was split into 3 plots to accommodate these treatments. Along the outside and between each plot there were border plants.

Sward productivity was measured by harvesting at ground level three random samples of two plants from each plot. There were six harvests at weekly intervals starting early in February. For each sample, leaf and non-leaf dry weight was determined, leaf area was measured, and root weights were estimated by taking a cylindrical core to a depth of $15 \mathrm{~cm}$ for each plant.

\section{RESULTS}

There were distinct treatment responses during the initial part of the regrowth period. Total or partial absence of residual leaf area (Treatments 1 and 2) resulted in a significant decrease in root weight, whereas in the presence of this leaf area the roots gained in weight (Table 1). Treatment 1 root weights did not exceed Day 0 values until Day 21, and they were still significantly lower than those in Treatment 3 on Day (28 Fig: I). Non-leaf dry 
IABLE 1: DRY WEIGHTS, LEAF AREA INDEX AND SPECIFIC LEAF AREA ON DAYS 0 AND 7.

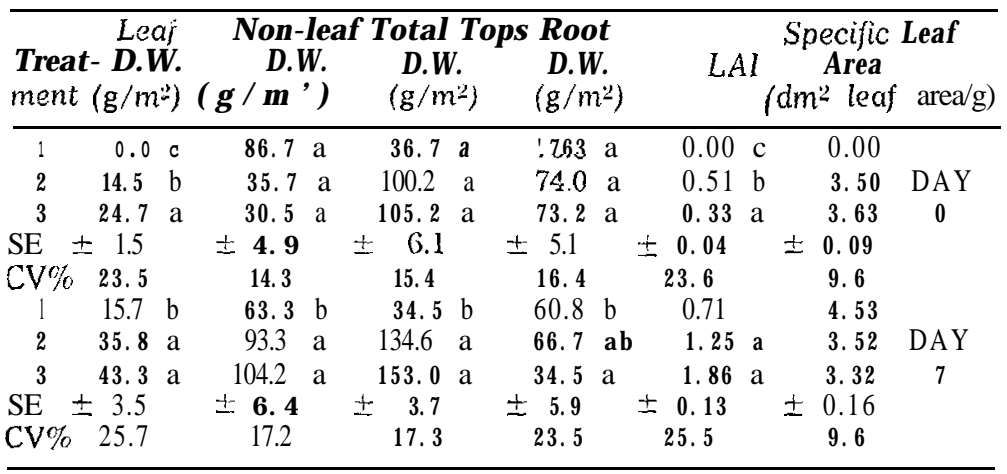

weights, representing mainly the stubble, fell during the first 7 days in Treatment 1, but increased to different degrees in the other two treatments. On the other hand, all plots gained in foliage, whether measures in terms of leaf weight or leaf area index. As a result of these changes, initial crop growth rates during the first 7 days were directly related to the severity of treatment.

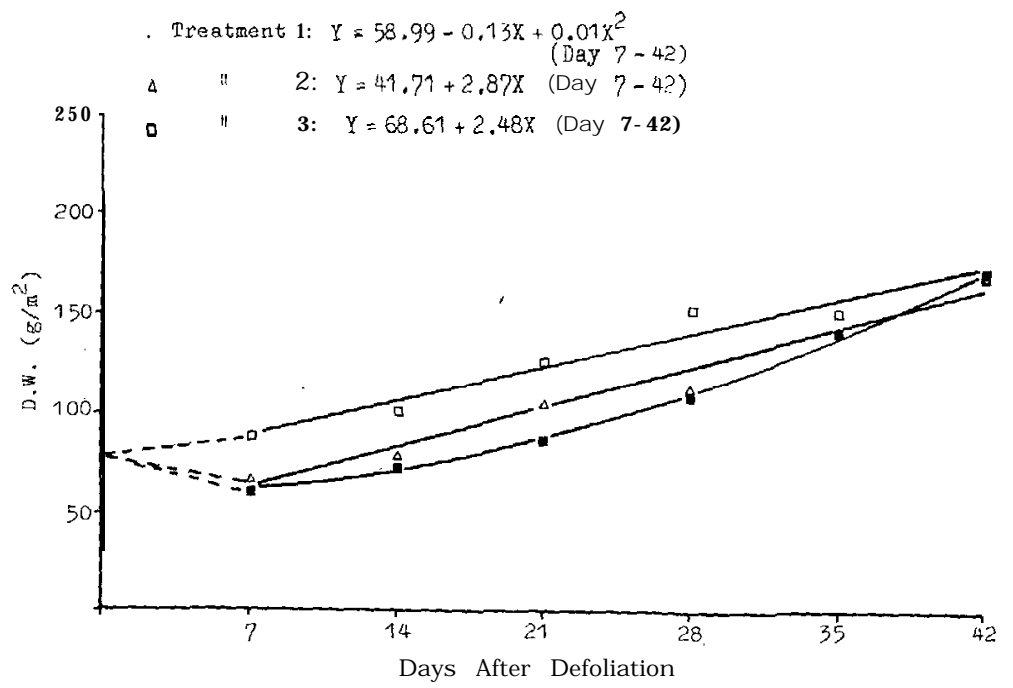

FIG. 1: Dry wei ght of roots $\left(\mathrm{g} / \mathrm{m}^{2}\right.$ of sward) following defoliation in the absence of residual leaf area (Treatment 1), in the presence of one-half (Treatment 2) or complete (Treatment 3) residual leaf area. 
With all leaves removed, mean crop growth rate was $-2.60 / \mathrm{cm}^{2} /$ day, compared with 3.87 with one-half and 7.73 with complete residual leaf area. However, the rapid attainment of a considerable leaf area, even in plants deprived of stubble leaves (Fig. 2), led to a marked recovery in growth. From Day 7 onwards, total top growth rates in Treatments 1 and 3 were similar, and after 4 weeks differences in top dry weights were not significant. Only total plant weights showed treatment effects until Day 28, owing to the initial setback suffered by the roots in Treatment 1 .

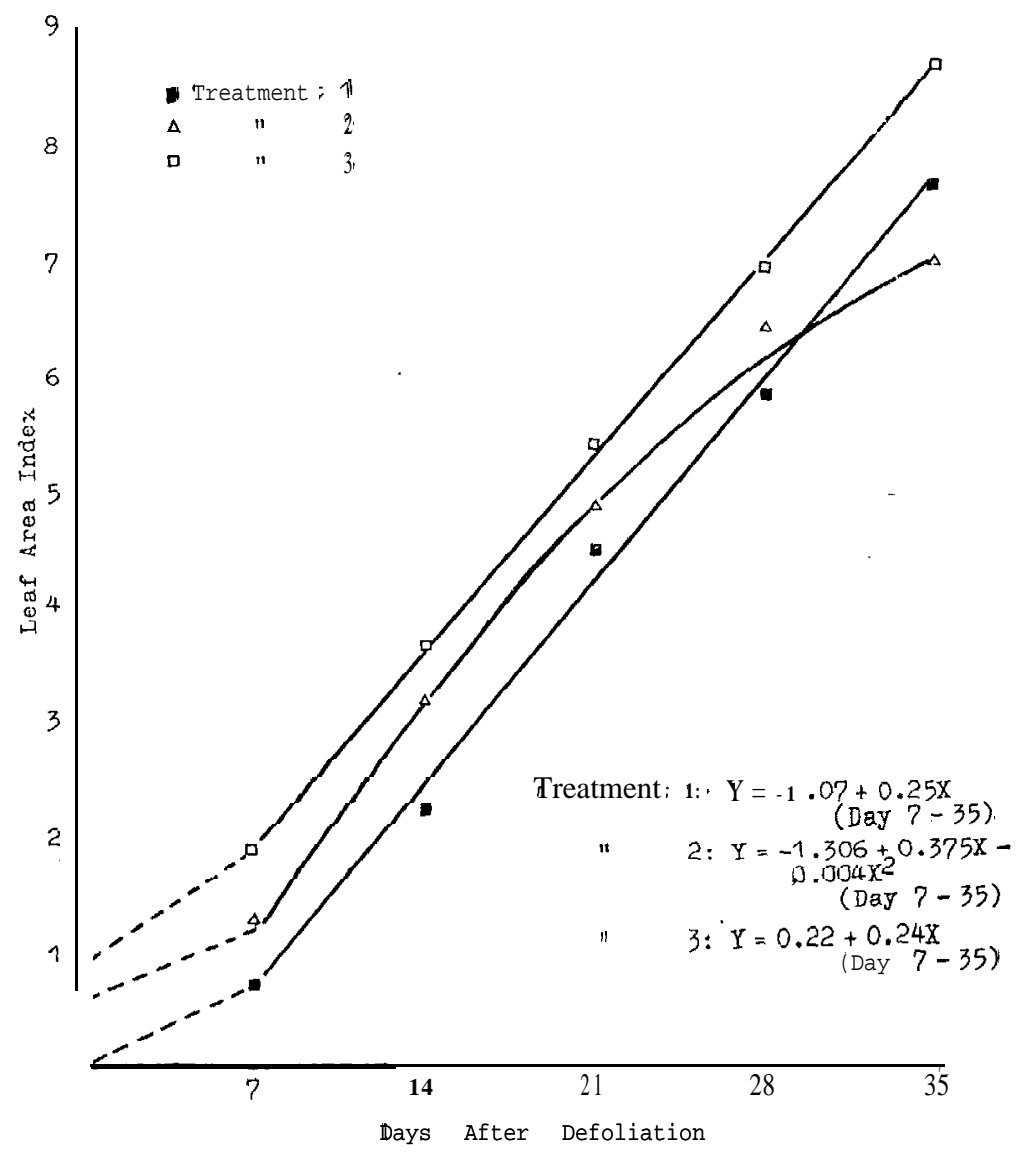

Fig. 2: Leaf area index of model lucerne swards which on defoliation had no \{Treatment 1), one-half (Treaiment 2), or complete (Treatment 3) residual leaf area. 
TABLE 2: NET ASSIMILATION RATES (g total D.W./dm² leaf area/week) AND RELATIVE LIGHT TRANSMISSION (\%) DURING THE FIRST TWO WEEKS.

\begin{tabular}{|c|c|c|c|}
\hline ime (days) & Treatmant 1 & Treatment 2 & Treaimanit 3 \\
\hline & \multicolumn{3}{|c|}{ Net assimilation rate $\left(\mathrm{g} / \mathrm{dm}^{2} / \mathrm{wk}\right)$} \\
\hline $0-7$ & -0.09 & 0.33 & 0.41 \\
\hline \multirow[t]{2}{*}{$7-14$} & 0.73 & 0.43 & 0.39 \\
\hline & \multicolumn{3}{|c|}{ Relative light transmission (\%) } \\
\hline 3 and 4 & 59.5 & 35.2 & 23.7 \\
\hline 13 and 14 & 10.5 & 7.2 & 6.2 \\
\hline
\end{tabular}

Under the conditions of this experiment, it was not possible to measure rates of photosynthesis and respiration directly. However, net assimilation rates $(\mathrm{NAR})^{*}$ were calculated and on two occasions during the early regrowth period light transmission readings to near ground level were taken with a ratio light meter (Table 2). Over the first period of 7 days, NAR was negative in Treatment 1 indicating a preponderance of respiration, as new leaves were produced at the expense of root and stubble weights. As expected, NAR in the other two treatments was positive in the same period but, in view of the high relative light transmission and low leaf area index, it was surprising that the values were not any higher. It is possible that the residual leaf area, which at that stage had barely been augmented by new leaves, was photosynthetically not very efficient. Several workers have demonstrated that the photosynthetic efficiency of previously shaded leaves is considerably less than in those with a history of bright illumination-e.g., Burnside and Bohning (1957), Pearce et al, (1968). Rate of photosynthesis also declines with age, and clearly these basal leaves were considerably older than those formed after defoliation. That there was a difference is suggested by comparing the high specific leaf area of new leaves appearing in Treatment 1 by Day 7 with the much lower values in the other two treatments which at that stage were still predominantly represented by residual leaves (Table I). A low specific leaf area indicates that each unit of area has a relatively large weight, and this suggests a high respiratory load. Further support for. this interpretation comes from the very high NAR of $0.73 \mathrm{~g} / \mathrm{dm}^{2} /$ week based on total plant weight in

"Calculated from

$$
\frac{\log , L_{2}-\log , L_{1}}{h-t_{1}} x-\frac{W_{2}-W_{1}}{L_{2}-L_{1}}
$$

where $L_{1}$ and $L_{2}$ are leaf area and $W_{1}$ and $W_{2}$ dry weight at times $t_{1}$ and $t_{2}$. 
Treatment 1 between days 7 and 14. Mean LAI during this period was 1.35 , almost identical with the size of the mainly residual foliage in Treatment 3 between Day 0 and 7 , when NAR reached only 0.41 , despite favourable light conditions. Evidently the newly formed leaves were photosynthesizing with great efficiency. Treatments 2 and 3 were also gaining in leaf area, as seen by considerable increases in LAI which had reached 2.93 and 3.63 respectively, on Day 14. These new leaves may have been responsible for maintaining NAR at much the same levels as in the previous week, despite the pronounced fall in light transmission.

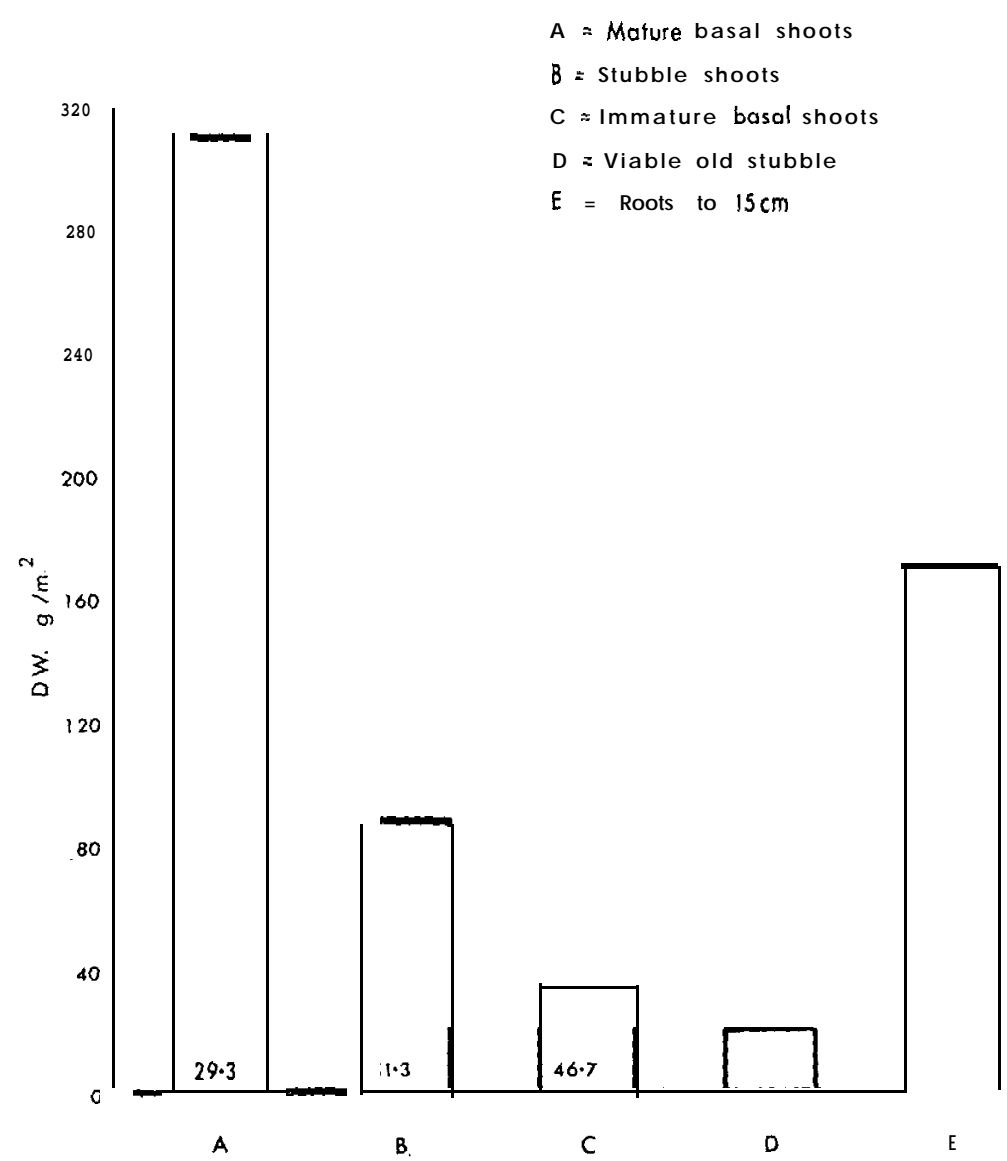

FIG. 3: Dry weight $\left(\mathrm{g} / \mathrm{m}^{2}\right.$ of sward) on Day 42 of different types of shoots, the stubble, and roots to a depth of $15 \mathrm{~cm}$. Figures at the base of columns represent the number of shoots/ 6 plants in each category. 
On Day 42, samples of the remaining population of plants were taken to determine to what extent shoots of different types had contributed to yield. Six plants from each plot were harvested and subdivided into (a) mature basal shoots which had elongated during the regrowth period, (b) immature basal shoots, a new crop originating from the crown, (c) stubble shoots, representing shoots in the axit of stubble leaves, and (d) old stubble which was considered to be still viable. Of these, the immature basal shoots were the most numerous (Fig. 3) but, as on average they weighed only $19 \mathrm{mg}$ each, they contributed less than $8 \%$ to total top yield. By far the biggest proportion of the yield (69\%) was attributable to mature basal shoots which individually weighed $268 \mathrm{mg}$. Shoots arising from axillary positions on the stubble were also reasonably heavy (193 $\mathrm{mg}$ on average) but their number was too small to have any substantial effect on total yield. The stubble itself contributed very little, and comparison with non-leaf dry weight at the start of the experiment (Table 1) indicated that considerable senescence must have taken place. These results differ from those of a growth cabinet experiment with spaced plants defoliated at a similar stage of growth (Keoghan, 1970) in which $44 \%$ of the final top yield came from shoots arising from stubble nodes. The comparable figure in this simulated sward of $19.5 \%$ illustrates the difference between spaced plants and sward conditions, although in either case the basal shoots were of greater importance. Leach (1970) working with spaced plants of Totana luceme has also shown that shoots arising from positions between 2 and 10 $\mathrm{cm}$ on the stubble contribute little to yield, because they are late in resuming extension growth.

\section{CONCLUSIONS}

From this and other experiments performed by us, together with evidence from the literature, it is possible to construct a generalized picture of the behaviour of de: foliated lucerne under sward conditions. Repeated close cutting weakens the plant and leads to a loss of root and possibly stubble weight, at least in the initial recovery period. Carbohydrates appear to be the main metabolites affected, and evidence is accumulating to show how they are acting as reserve materials and as respiratory substrate, although the relative importance of these two functions is still under debate. In addition to biochemical change, there is almost certainly some reduction in root absorption. In these circumstances, the possible role of the residual leaf area remaining on the stubble comes into prominence. 
However, it would appear that in the field this may not be anything like as important as in spaced plants, Because of their previous history in the shade of the canopy above them and possibly also their age, these leaves are unlikely to be very effective in photosynthesis. More important by far are the new leaves which are produced after cutting. There is the further point that in a dense sward few basal Feaves remain on mature shoots, as shading accelerates leaf senescence and death at the base of the canopy. In the face of these findings, one could still argue that a tall stubble may be beneficial if it provides plenty of sites for the formation of axillary shoots. However, even this possibility does not appear to be of any great consequence in a sward in which the major part of the recovery growth seems to come from basal shoots arising from the crown region. Naturally there could be genetic differences in this respect, especially in prostrate types of lucerne. However, in upright genotypes few if any advantages accrue from raising the cutting height above about $5 \mathrm{~cm}$ in the hope of encouraging more rapid recovery. If a lucerne stand has been mismanaged by repeated cutting at immature stages of growth, the remedy lies in increasing the length of the recovery period until new basal buds are ready to take over the growth of the plant following defoliation.

\section{REFERENCES}

Burnside, C. A.; Bohning, R. H., 1957: PI. Physiol. 32: 61-3. Brougham, R. W., 1956: A ust. J. agric. Res., 7: 377-87.

Davidson, J. L.; Donald, C. M., 1958: Aust. J. agric. Res., 9: 53-72.

Davidcon, J. L.; Milthorpe, F L., 1966: Ann. Bot., 30: 185-98.

Graber, L. F.; Nelson, N. T.; Lueckel, W. A.; Albert, W. B. 1927:

Bull. Wis. agric. Exp. Stn 80.

Hodgkinson, K. C.; 1970: Proc. XI int. GrassId Congr.: 559-62.

Keoghan, J. M., 1966: M.Agr.Sc. thesis, Lincoln Coll., Univ. of Canterbury (lodged in Lincoln Coll. Library).

1970: Ph.D. thesis. Lincoln Coll.. Univ. of Canterbury (lodged in Lincoln Coll. Library).

Langer, R. H. M.; Steinke, T. D., 1965: J. agric. Sci., Camb., 64: 291-5.

Leach, G. J., 1968: Aust. J. agric. Res., 19: 517-30.

1970: Proc. XI int. G rassld Congr.: 562-6

May, L. H., 1960: Herb. Abstr., 30: 239-45.

Mitchell, K. J.; Denne, M.P., 1967: in The Lucerne Crop, ed. R. H. M. Langer, Wellington, Reed. 22-7.

Pearce, R. B.; Brown, R. H.; Blaser, R. E., 1968: Crop Sci., 8: 677-80.

Silva, J. P., 1968: Diss. Abstr. 29.

Smith, Dale, 1962: Crop Sci., 2: 75-8.

Watson; D. J., 1947: Ann. Bot., 11: 41-76.

Weinmann, H., 1948: J. Br. Grassld Soc., 3: 115-40. 


\section{LUCERNE GROWTH AFTER DEFOLIATION}

\section{DISCUSSION}

Sprague (U.S.A.) asked if the quantity and types of protein present had been considered as reserve substances. Langer said they had been considered but not measured. In grasses, under severe defoliation it was assumed that proteinaceous substances were used in some way, but nothing had been found for lucerne. Smith (U.S.A.) asked if the reserves used in new root growth had been taken into account. Langer thought that Graber's observations had been oversimplified. Lucerne should be considered as a bank. The whole metabolic system was fluid and it was downward movement that was important. Forde commented that, for temperate grasses following defoliation, there was a rapid redistribution of reserves. For several days after, the various portions of the plant functioned separately.

Leonard said residual leaves appeared to have a lower photosynthetic capacity than those newly produced. Therefore, would complete removal be the best cutting regime? Keoghan considered that there was no advantage in leaving residual leaves. In the field, basal leaves were lost by senescence: In the ideal situation buds were elongating to produce new leaves. Forde suggested that the residual leaves which had been growing at low light levels might adapt photosynthetically to the increased light levels following defoliation. Langer said that this had not been examined anatomically but there was some evidence that adaptation did take place. It was a suggestion that could well be followed up. Brougham commented that, in white clover, the residual leaves had a higher than normal chlorophyll B content, but that they adapted after exposure to high light levels. Such leaves could be important from the persistency aspect.

Heath (U.S.A.) stated that on the field trip to Ashley Dene he had noticed E-year-old lucerne stands carrying eight sheep per acre and that they appeared to be very closely grazed. Was this considered good management? Langer replied that that was the winter picture and that such close defoliation was not important. What was important was, in the actively growing period, to have such management as to give ample time for recovery growth. 